\title{
Scientific Ocean Drilling Behind the Assessment of Geo-Hazards from Submarine Slides
}

\author{
by Angelo Camerlenghi, Roger Urgeles, Gemma Ercilla, and Warner Brückmann
}

doi:10.2204/iodp.sd.4.14.2007

\section{Introduction}

The workshop 'Scientific Ocean Drilling Behind the Assessment of Geo-hazards from Submarine Slides' was held on 25-27 October 2006 in Barcelona (Spain). Fifty mainly European scientists and industry representatives attended from a wide spectrum of disciplines such as geophysics, stratigraphy, sedimentology, paleoceanography, marine geotechnology, geotechnical engineering, and tsunami modeling.

\section{Submarine Slides and Scientific Drilling}

Submarine slides pose societal and environmental risks to offshore infra-structures (platforms, pipelines, cables, sub-sea installations), and coastal areas including tsunamis (Fig. 1), and they can dramatically change the marine environment. Triggering mechanisms include earthquakes, gas hydrate dissociation, instability of volcanic flanks, and fluid flow. Research on submarine slides may also help understand paleoseismicity, climate change, and sedimentary facies on basin evolution relevant to hydrocarbon reservoir characterization.

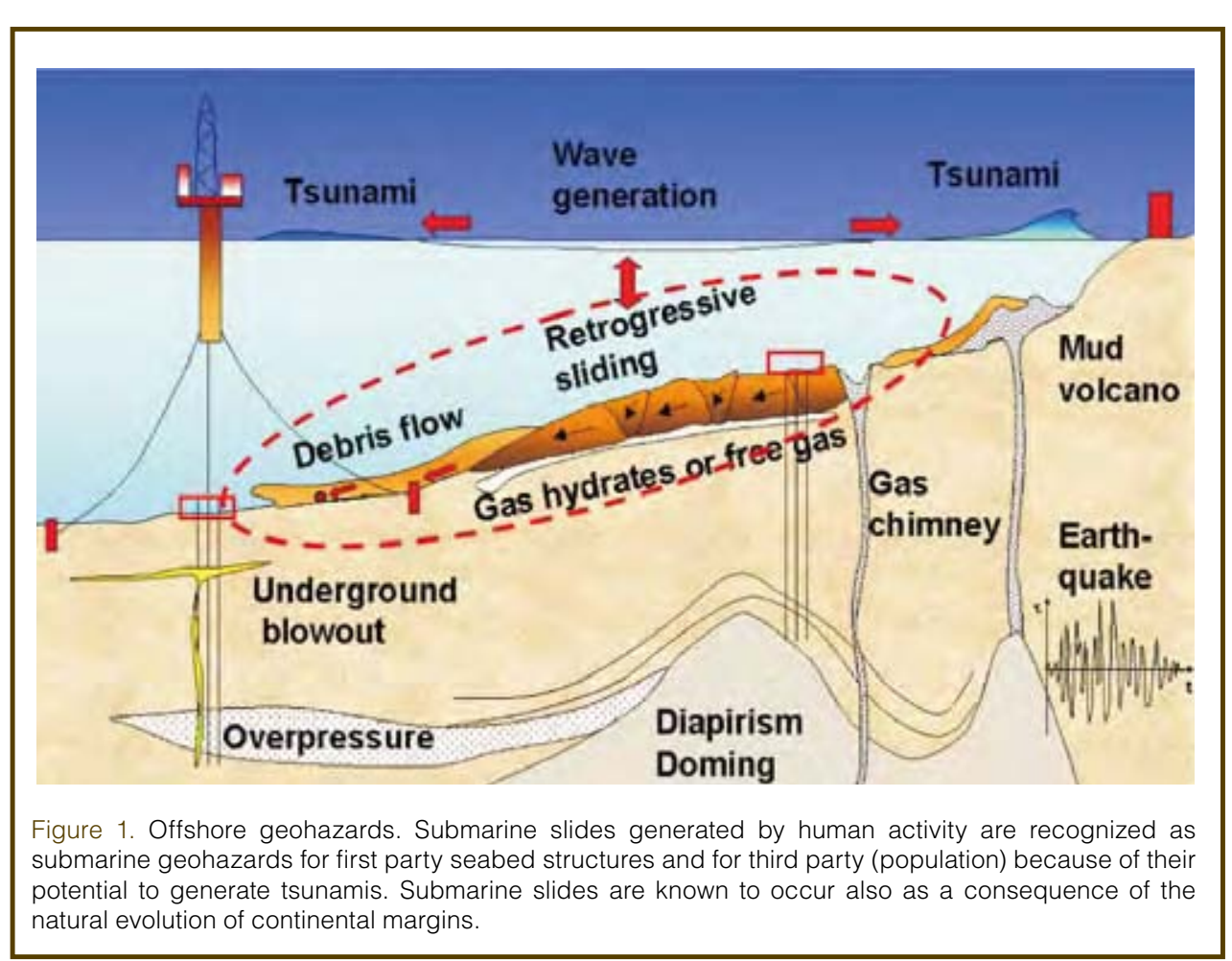

The Storegga Slide off Norway and close to the Ormen Lange Gas Field remains the only medium to large submarine mass movement that has been investigated to confirm the geometry as well as the in situ stresses and their evolution at the time of failure ('Ormen Lange Project', Solheim et al., 2005). This study concluded that extensive geophysical surveys, seabed characterization, geotechnical boring, and in situ measurements both inside and outside the slide bodies are needed to reliably define and constrain the lateral variability of geotechnical parameters (Fig. 2). Drilling is required to address the following four questions.

What is the frequency of submarine slides? Drilling and appropriate high resolution stratigraphic and geo-chronologic tools can establish the history and frequency of submarine slope failures. Currently only a few mega events such as the Storegga Slide (roughly 8150 years old) have been dated with sufficient accuracy. Many medium and small recent submarine slides are known to have higher rates of recurrence (Hühnerbach and Masson, 2004).

What is the tsunamigenic potential of a submarine slide? Tsunami generation is controlled not only by slide geometry (slide volume, area, water depth) but also by slide kinematics (slide acceleration and velocity). Sampling and in situ measurements are needed to understand the rheology of the slide. Evidence suggests that shearing of the landslide mass is significantly different at its base compared to its top, which translates into a distinct profile of physical properties (Expedition 308 Scientists, 2005). Insights obtained through sampling of the failed sediments may help predict the failure dynamics of a yet stable slope.

Do precursory phenomena of slope failure exist? We need to determine which transient signs might indicate imminent slope instability and improve our capability to predict events of slope instability. Consequently, it 


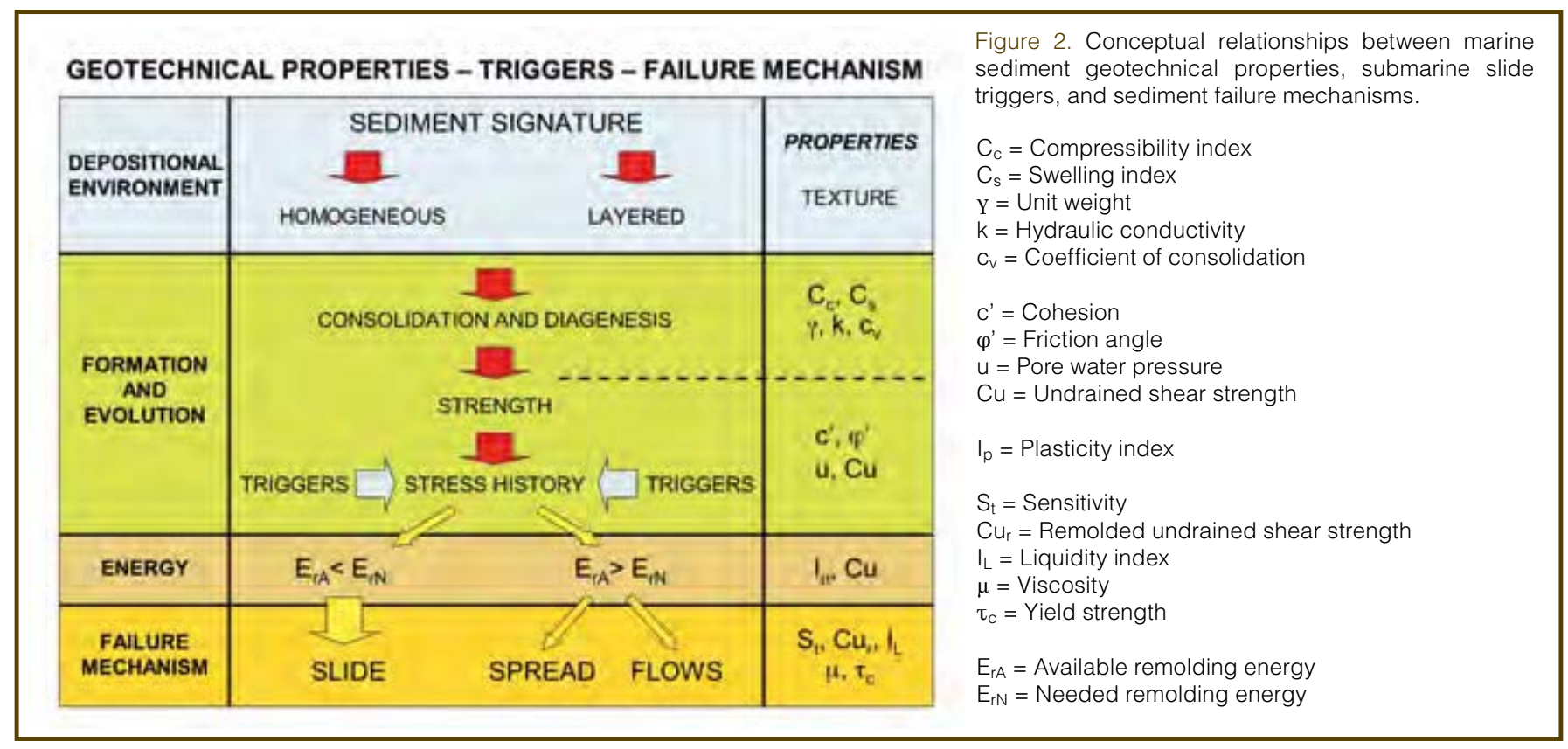

is necessary to conduct long-term monitoring of pore pressure, temperature and hole inclination in slopes where failure might occur in a relatively short term. Investigation of the geochemistry of pore fluids may tell if clay minerals such as smectite released mineral water due to shear. Drilling and monitoring are also important to describe how slow deformation of slopes (creep) occurs and to relate seismic reflection features to active sediment deformation.

\section{What makes up weak layers in continental slope sediments?} Submarine landslides are often found to be rooted at one or more stratigraphic levels. These levels likely represent a "weak layer" that plays a fundamental role in landslide initiation and in determining slide volume and geometry. In glaciated margins weak layers have been identified in contouritic deposits that were formed during interglacial periods and were rapidly buried under thick glacial-marine deposits (Bryn et al., 2005). The occurrence of weak layers in nonglaciated margins is poorly understood.

\section{Hypotheses and Models}

While a general relationship between slope instability and natural climatic cycles has been demonstrated on the Northern European margin (Solheim et al., 2005), the mechanisms behind the generation of submarine slope instability are still poorly understood because of lack of deep penetration sediment cores. There are at least two hypotheses and models that could be tested through drilling.

1. The focusing of fluids and lateral transfer of stresses can trigger slides. Two-dimensional modeling of the New Jersey margin suggests that lateral fluid flow in permeable beds under differential overburden stresses produces fluid pressures that approach the lithostatic stress where overburden is thin. This transfer of pressure may cause slope failure initiation at the base of the continental slope
(Dugan and Flemings, 2000). IODP Expedition 308 tested a hydrogeologic model by which pore fluids are laterally advected under certain loading and stratigraphic conditions (Behrmann et al., 2006). Excess pore pressure in highly permeable sediments is transferred to zones of lower overburden with an important effect on slope stability. Similar pore fluid advection might be caused by glacial loading of permeable sediments (e.g., Storegga Slide or Antarctic Peninsula margin).

2. The Clathrate Gun Hypothesis (Kennett et al., 2000) states that methane emissions from gas hydrate dissociation induced by climate change and bottom water warming is related to submarine slide activity. The unroofing of buried hydrate-bearing sediments by submarine slides enhances methane emissions from the seafloor by instantaneously decreasing the confining pressure. The carbon isotope chemistry and the assemblages of benthic calcareous foraminifera close to paleo-slide heads might contain a record of paleo-methane seeps as well as other (micro) biological indicators.

\section{Conclusions}

Geohazards have mainly been addressed in scientific drilling campaigns as a complementary goal. Future and dedicated drilling experiments should address mega slides as well as small to medium slides. Understanding the mechanics of the less frequent, but potentially catastrophic, mega slides requires a large amount of site survey data and might require a multi-expedition effort. Smaller slides occur with a frequency close to that of natural hazards considered in the determination of the 500 years risk. They may cause damage to seabed installations and generate tsunami waves that, although being relatively small, may cause onshore damage and casualties in densely populated coastal regions. More than one small to medium submarine slide can be 
addressed effectively in one single drilling expedition, but may require a multi-platform approach supporting stratigraphic drilling, geotechnical drilling, and installation of borehole and seafloor observatories.

High-resolution seafloor mapping, possibly using deeptowed devices or remotely operated vehicles (ROV), and the integration of bathymetric and backscatter information will be necessary to obtain the best morphologic and acoustic characterization of recent slides. High-resolution 3-D seismic data acquisition will be important to define targets within the unfailed sediments, scar and detachment area, evacuation zone, and accumulation area within a slide complex. For appropriate post-cruise geotechnical analyses, the drilling system must obtain high-quality undisturbed geotechnical samples. Existing advanced piston coring and narrow kerf rotary drilling were considered most prospective for implementation on IODP drilling vessels. Long term monitoring of key parameters in boreholes (e.g., pore pressure, hole inclination, or ambient acoustic noise) can utilize the well-established Circulation Obviation Retrofit Kit (CORK) technology. A link with existing seafloor observatories initiatives was recognized as very important for remote and real-time monitoring.

Drilling to understand submarine slope instability is perceived as highly multidisciplinary. Drilling proposals should address scientific questions outlined above in a variety of geological environments. The teams of proponents should include a wide range of tsunami experts, sedimentologists, paleoceanographers, geotechnical engineers, and deep-sea observatories. The international community will further stress the importance of Geohazards research during the upcoming IODP Geohazards Workshop in Summer 2007 (see workshop announcements on page 51 ).

\section{Acknowledgements}

The workshop was funded by the European Science Foundation within the Workshops on Marine Research Drilling (MAGELLAN) series. Co-funding was provided by the European Consortium for Ocean Drilling (ECORD), the Consejo Superior de Investigaciones Científicas (CSIC), the Faculty of Geology of the University of Barcelona (UB), the IGCP Project 511 (Submarine Mass Movements and their Consequences), and the Spanish Ministry of Education and Science (MEC).

\section{References}

Behrmann, J.H., Flemings, P.B., John, C.M., and IODP Expedition 308 Scientists, 2006. Superfast sedimentation, overpressures and focused fluid flow, Gulf of Mexico continental margin. Sci. Drill., 3:12-17, doi: 10.2204/iodp.sd.2.03.2006

Bryn, P., Berg, K., Stoker, M.S., Haflidason, H., and Solheim, A., 2005. Contourites and their relevance for mass wasting along the Mid-Norwegian Margin. Mar. Petr. Geol., 22: 85-96.

Dugan, B., and Flemings, P.B., 2000. Overpressure and fluid flow in the New Jersey continental slope: implications for slope failure and cold seeps. Science, 289:288-291.

Expedition 308Scientists, 2005. Overpressure and fluid flow processes in the deepwater Gulf of Mexico: slope stability, seeps, and shallow-water flow. IODP Prel. Rept. 308. doi:10:2204/iodp. pr.308.2005

Hühnerbach, V., and Masson, D.G., 2004. Landslides in the North Atlantic and its adjacent seas: an analysis of their morphology, setting and behaviour. Mar. Geol., 213:343-362

Kennett, J.P., Cannariato, K.G., Hendy, I.L., and Behl, R.J., 2000. Carbon isotopic evidence for methane hydrate instability during Quaternary interstadials. Science, 288: 128-133.

Solheim, A., Bryn, P., Sejrup, H.P., Mienert, J., and Berg, K., 2005. Ormen Lange-an integrated study for the safe development of a deep-water gas field within the Storegga Slide Complex, NE Atlantic continental margin; executive summary. Mar. Pet. Geol., 22:1-9.

\section{Authors}

Angelo Camerlenghi, ICREA and GRC Geociències Marines, Departament d'Estratigrafia, Paleontologia i Geociències Marines, Universitat de Barcelona, C/ Martí i Franquès, s/n, E-08028 Barcelona, Spain, e-mail: angelo. camerlenghi@icrea.es.

Roger Urgeles, GRC Geociències Marines Departament d'Estratigrafia , Paleontologia i Geociències Marines, Universitat de Barcelona C/ Martí i Franquès, s/n, E-08028 Barcelona, Spain.

Gemma Ercilla, Departamento de Geología Marina y Oceanografia Física, Instituto de Ciencias del Mar, CMIMACSIC, Paseo Marítimo de la Barceloneta 37-49, E-08003 Barcelona, Spain.

Warner Brückmann, Leibniz-Institute for Marine Sciences, IFM-GEOMAR, Wischhofstr. 1-3, D-24148 Kiel, Germany.

\section{Related Web Links}

http://www.esf.org

http://www.geohazards.no/IGCP511

\section{Photo and Figure Credits}

Fig. 1. Courtesy of Norwegian Geotechnical Institute (NGI) and the International Centre for Geohazards (ICG)

Fig. 2. by J. Locat, Laval University, Quebec, Canada. 